\title{
Identification of a new resistance locus against the rice gall midge, Orseolia oryzae (Wood-Mason), in Thai rice landrace MN62M
}

\author{
Phikul Leelagud \\ Ubon Ratchathani Rice Research Center
}

Sakda Kongsila

Ubon Ratchathani Rice Research Center

Phanchita Vejchasarn

Ubon Ratchathani Rice Research Center

Kulchana Darwell

Phrae Rice Research Center

\section{Yotwarit Phansenee}

Ubon Ratchathani Rice Research Center

Arissara Suthanthangjai

Ubon Ratchathani Rice Research Center

Chanita Uparang

Ubon Ratchathani Rice Research Center

\section{Rungnapa Kawichai}

Ubon Ratchathani Rice Research Center

\section{Punnipa Yajai}

Phrae Rice Research Center

Kunlayaa Boonsa-nga

Chiang Rai Rice Research Center

\section{Varapong Chamarerk}

Rice Department

Jirapong Jairin ( $\nabla_{\text {jirapong.j@rice.mail.go.th ) }}$

Ubon Ratchathani Rice Research Center https://orcid.org/0000-0003-4283-820X

Original article

Keywords: Orseolia oryzae, rice gall midge, restistant rice varieties, pest resistance, Thailand

Posted Date: December 18th, 2019

DOI: https://doi.org/10.21203/rs.2.19147/v1 
License: (c) (i) This work is licensed under a Creative Commons Attribution 4.0 International License. Read Full License 


\section{Abstract}

\section{Background}

The rice gall midge (RGM), Orseolia oryzae (Wood-Mason), is one of the most destructive insect pests of rice, and it causes significant yield losses annually in Asian countries. The development of resistant rice varieties is considered as the most effective and economical approach for maintaining yield stability by controlling RGM. Identification of resistance genes will help in marker-assisted selection (MAS) to pyramid the resistance genes and develop a durable resistance variety against RGM in areas with frequent outbreaks.

\section{Results}

A mitochondrial gene, cytochrome $\mathrm{C}$ oxidase I (COI), was used to analyze the genetic diversity among Thai RGM populations. The phylogenetic tree indicated that the Thai RGM populations were homogeneously distributed throughout the country, except for some populations in central and northeast Thailand that probably became isolated from the main population. The reactions of the resistant rice varieties carrying different resistance genes revealed different RGM biotypes in Thailand. The Thai rice landrace MN62M showed resistance to all RGM populations used in this study. We identified a novel genetic locus for resistance to RGM, designated as GM12, on the short arm of rice chromosome 2. The locus was identified using linkage analysis in $144 \mathrm{~F} 2$ plants derived from a cross between susceptible cultivar KDML105 and RGM-resistant cultivar MN62M with single nucleotide polymorphism (SNP) markers and F 2:3 phenotype. The locus was confirmed and mapped using SNP and simple sequence repeat (SSR) markers surrounding the target chromosomal location. Finally, the locus was mapped between two flanking markers, RM6800 and S2_419160.

\section{Conclusions}

We identified a new RGM resistance gene, GM12, on rice chromosome 2 in the Thai rice landrace MN62M. This finding yielded SNP and SSR markers that can be used in MAS to develop cultivars with broad-spectrum resistance to RGM. The new resistance gene provides important information for the identification of RGM biotypes in Thailand and Southeast Asia.

\section{Background}

The rice gall midge (RGM), Orseolia oryzae (Wood-Mason) (Diptera: Cecidomyiidae), is a major pest of rice and widely spread in Asia. Its economic impacts are important for major rice-producing countries, especially in South and Southeast Asia (Bentur et al. 2016; Ramasamy et al. 1996). The larvae of RGM feed on growing tips inside rice plant tillers, modulate host cell activities, and change regular tillers of rice plants into tubular leaf sheath galls called silver shoots that allow the RGM to complete its life cycle (Jagadeesha Kumar et al. 2009; Rajamani et al. 2004; Zhao et al. 2015). No panicle is formed in the affected tillers, leading to yield losses. Attempts to identify the genetic diversity of RGM have revealed the 
existence of genetic variations in RGM populations in Thailand (Janique et al. 2017; Jairin et al. 2009; Tayathum et al. 2004). Previous studies have suggested that RGM populations in South and Southeast Asia are isolated (Janique et al. 2017; Katiyar et al. 2000).

The different reactions of resistant rice varieties to RGM populations have revealed various gall midge biotypes (Bentur 1987). The biotypes differ in host range, depending on the resistance genes of the cultivars. Variations in the repeat region in the mitogenome have been proposed to differentiate the RGM biotypes (Atray et al. 2015). Existence and emergence of new virulent RGM biotypes have been reported, and the resistance genes in several RGM-resistant rice varieties were ineffective against such biotypes (Bentur et al. 2016). To identify the biotype of Thai populations, a differential set of resistant rice varieties with known resistance genes needs to be developed. Therefore, germplasm screening and identification of resistance genes in Thai rice germplasm are necessary for classifying the RGM biotypes in Thai populations.

Exploitation of host plant resistance to RGM is an economical and environment-friendly approach to manage the pest (Khush 1977). Breeding resistant rice varieties is an economically acceptable method for managing RGM. To date, 11 major resistance genes, designated GM1-11, that confer resistance to RGM populations have been identified, mostly in South Asia (Bentur et al. 2016; Venkanna et al. 2018). Of the 11 resistance genes, 8 genes (GM1, GM2, GM3, GM4, GM6, GM7, GM8, and GM11) have been mapped to rice chromosomes. Three of these genes, GM2 (NB-ARC), GM3 (NB-ARC), and GM4 (NB-LRR), have been functionally validated (Sama et al. 2014; Bentur et al. 2016; Divya et al. 2015). Unfortunately, most resistant varieties with GM2-GM10 are susceptible to RGM populations found in Thailand. Only a variety carrying GM1, W1263, is resistant to some RGM populations in Thailand, indicating that the RGM biotypes in Thailand and India are different. Although the infested tillers of W1263 (GM1) did not produce galls, the infested plants showed severe damage, with stunting, and produced more ineffective tillers. We believe that the resistant mechanism of GM1 can reduce the RGM population in the next generation. Pyramiding GM1 with other resistance genes with different mechanisms can help us to develop a durable and broad-spectrum resistant rice variety.

The last RGM resistance gene, GM11, was reported in 2010. Here, we have reported a new broadspectrum RGM resistance gene in the Thai rice landrace 'Muey Nawng 62M (MN62M)' that confers resistance to the RGM populations in Thailand. MN62M is an indica glutinous rice that mostly grows in rain-fed areas north of Thailand. It is an important gall midge-resistant rice cultivar in Thailand (Oupkaew et al. 2011; Pusadee et al. 2014). To the best of our knowledge, this is the first report of an RGM resistance gene in a Thai rice landrace. The new resistance gene against RGM identified in this study will provide single nucleotide polymorphism (SNP) and simple sequence repeat (SSR) markers for markerassisted selection (MAS) in future breeding programs. Gene pyramiding is considered as a practical tool for achieving durable RGM resistance in rice (Suvendhu et al. 2014; Venkanna et al. 2018). The pyramiding of GM1 and the new resistance gene identified in this study may increase the level of resistance to Thai as well as Southeast Asian RGM populations. 


\section{Results}

Genetic diversity and RGM biotypes in Thailand

The genetic diversity of RGM across Thailand was examined using cytochrome C oxidase I (COI). Cluster analysis of the similarity scores is shown in Fig. 1. Eighteen RGM populations from north, central, and northeast Thailand were classified into two distinct groups. The first group consisted of populations collected from rice fields in Thailand. The second group was composed of two outgroup populations, RGM from Kerala, South India, and weed gall midge from dallisgrass (Paspalum distichum L.) collected from the Chiang Rai (CRI) Province, Thailand. Surprisingly, the COI sequence of the dallisgrass gall midge is closely related to that of the RGM from Kerala. The results showed that the RGMs from Thailand and India were different on the basis of the partial COI sequences, indicating that the RGM species in Asia are complex. Almost all RGM populations in this study were homogeneously distributed throughout Thailand, except for some populations that became isolated from the main population. The dendrogram suggested the existence of two distinct groups of RGM populations in Thailand. The first group was composed of populations from the central plains and northeast of Thailand (except Buriram [BRR]), and the second group consisted of RGMs from BRR, CNT, and LBR (Fig. 1). According to our results, the genetic diversity was not strongly related to geographical repartition and did not show any correlation with the biotypes.

The reaction of 13 resistant rice varieties carrying nine differential RGM resistance genes revealed four distinct RGM biotypes from different parts of Thailand (Table 1). The RGM resistant varieties, Phalguna (GM2), Velluthacheera (GM3), Abhaya (GM4), ARC5984 (GM5), RP2333-156-8 (GM7), Agani (GM8), and BG380-2 (GM10), were susceptible to all RGM populations used in this study. W1263, Sam Sa Mai, MN62M, and RD53 were resistant to some RGM populations. Only MN62M was resistant to all RGM populations. Therefore, MN62M and W1263 can be used as differential varieties to characterize the RGM biotypes in Thailand. Two Thai rice varieties, Sam Sa Mai and RD53, that carry unknown RGM resistance genes, can also be considered for use as differential varieties after the resistance genes have been identified. 
Table 1

Reactions of some rice varieties to gall midge, gall midge resistance genes in rice, their chromosomal locations, and spectrum of resistance across biotypes

\begin{tabular}{|c|c|c|c|c|c|c|c|c|c|c|}
\hline \multirow{2}{*}{$\begin{array}{l}\text { Rice } \\
\text { genotype }\end{array}$} & \multirow{2}{*}{$\begin{array}{l}\mathrm{R} \\
\text { gene }\end{array}$} & \multirow{2}{*}{$\begin{array}{l}\text { Chr } \\
\text { No. }\end{array}$} & \multicolumn{8}{|c|}{ Rice gall midge population } \\
\hline & & & $\begin{array}{l}\text { KSG- } \\
\text { BRR }\end{array}$ & $\begin{array}{l}\text { DSK- } \\
\text { CMI }\end{array}$ & $\begin{array}{l}\text { MUA- } \\
\text { PRE }\end{array}$ & $\begin{array}{l}\text { KYM- } \\
\text { MHS }\end{array}$ & $\begin{array}{l}\text { KMR- } \\
\text { UBN }\end{array}$ & $\begin{array}{l}\text { PPS- } \\
\text { NKI }\end{array}$ & $\begin{array}{l}\text { BKA- } \\
\text { NAN }\end{array}$ & $\begin{array}{l}\text { MUA- } \\
\text { CRI }\end{array}$ \\
\hline W1263 & $\mathrm{Gm} 1$ & 9 & $\mathrm{R}$ & $\mathrm{R}$ & S & S & $S$ & $\mathrm{R}$ & S & S \\
\hline Phalguna & $\mathrm{Gm} 2$ & 4 & $S$ & $S$ & S & S & $S$ & S & S & S \\
\hline SIAM29 & $\mathrm{Gm} 2$ & 4 & $S$ & $S$ & $S$ & S & $S$ & $S$ & S & S \\
\hline Velluthacheera & Gm3 & 4 & $S$ & $S$ & $S$ & S & $S$ & S & S & S \\
\hline Abhaya & Gm4 & 8 & $S$ & $S$ & $S$ & $S$ & $S$ & $S$ & $S$ & $S$ \\
\hline ARC5984 & Gm5 & $?$ & $S$ & $S$ & $S$ & $S$ & $S$ & $S$ & $S$ & S \\
\hline RP2333-156-8 & Gm7 & 4 & $S$ & $S$ & $S$ & $S$ & $S$ & $S$ & $S$ & $S$ \\
\hline ARC10659 & Gm7 & 4 & $S$ & $S$ & $S$ & $S$ & $S$ & $S$ & $S$ & $S$ \\
\hline Aganni & Gm8 & 8 & $S$ & $S$ & $S$ & $S$ & $S$ & $S$ & $S$ & $S$ \\
\hline BG380-2 & Gm10 & $?$ & $S$ & $S$ & $S$ & $S$ & $S$ & $S$ & $S$ & $S$ \\
\hline Sam Sa Mai & $?$ & $?$ & $\mathrm{R}$ & $\mathrm{R}$ & $\mathrm{R}$ & $\mathrm{R}$ & $\mathrm{R}$ & $S$ & $S$ & $S$ \\
\hline MN62M & Gm12 & 2 & $\mathrm{R}$ & $\mathrm{R}$ & $\mathrm{R}$ & $\mathrm{R}$ & $\mathrm{R}$ & $\mathrm{R}$ & $\mathrm{R}$ & $\mathrm{R}$ \\
\hline RD53 & $?$ & $?$ & $\mathrm{R}$ & $\mathrm{R}$ & $\mathrm{R}$ & $\mathrm{R}$ & $S$ & $S$ & $S$ & $S$ \\
\hline KDML105 & None & - & $S$ & $S$ & $S$ & $S$ & $S$ & $S$ & $S$ & $S$ \\
\hline TN1 & None & - & $S$ & $S$ & $S$ & $S$ & $S$ & $S$ & $S$ & $S$ \\
\hline
\end{tabular}

Inheritance of RGM resistance in MN62M

The parental varieties, KDML105 and MN62M, $F_{1}$, and derived $F_{2: 3}$ families were evaluated for RGM resistance in the greenhouse during the wet season of 2018 (Additional file 1: Table S1). The average damage to KDML105 and MN62M was 9 (100\% plant with gall) and 0 (no plant with gall), indicating susceptible and resistant reactions to RGM, respectively. The frequency distribution of the damage severity (percentage of plants infested with galls) in $300 \mathrm{~F}_{2: 3}$ families from the KDML105 $\times$ MN62M population is shown in Fig. 2. The inheritance pattern of RGM resistance in MN62M was studied in the $F_{1}$ and $F_{2: 3}$ populations. The $F_{1}$ plants were susceptible, whereas the $F_{3}$ families showed a segregation ratio of 1 resistant: 3 susceptible families $\left(X^{2}=0.64 ; P=0.42\right)$ when evaluated against RGB from Ubon 
Ratchathani (UBN) province. The inheritance studies revealed the presence of a single recessive gene that controlled the resistance in MN62M.

\section{Linkage map and QTL analysis}

Of the $300 \mathrm{~F}_{2}$ progenies derived from the KDML105 $\times$ MN62M cross, $144 \mathrm{~F}_{2}$ plants with clear phenotypic data of $F_{2: 3}$ families were selected for SNP genotyping and linkage map construction. A total of 1,365 polymorphic SNPs and JoinMap 4.1 were used to construct the linkage map. The linkage map spanned a total genetic distance of $1,743.3 \mathrm{cM}$ on all 12 chromosomes, with linkage groups ranging from $81.1 \mathrm{cM}$ (chromosome 12) to $191.2 \mathrm{cM}$ (chromosome 1). The number of markers mapped to each chromosome varied from 59 (chromosome 10) to 154 (chromosome 1).

The linkage maps for KDML105/MN62M and plant damage data were used to map the QTL associated with RGM resistance. The QTL analysis was performed using multiple QTL model (MQM) mapping in MapQTL 6.0 with 1,000 permutations. The MQM mapping analysis detected only a major QTL for RGM resistance on the proximal tip of rice chromosome 2 (Fig. 3, Additional file 2: Figure S1) with a high LOD score of 65.1 and phenotypic variance explained (PVE) of 87.5\% between SNP markers S2_76222 and S2_419160. The resistance locus showed positive additive effect values, indicating the allele that confers resistance to RGM is from MN62M. Then, the gene locus was designated as GM12.

To confirm the chromosomal location of the GM12 locus, SSR markers covering the target locus were selected and used for the parental polymorphism survey. Of the 25 SSR markers, only three markers showed polymorphism between the parents. Then, SSR and SNP markers on the short arm of chromosome 2 were used to construct the linkage map and perform QTL analysis. The new RGM resistance gene in MN62M was located on chromosome 2 between SSR and SNP markers RM6800 and S2_419160, respectively (Fig. 4). To the best of our knowledge, no RGM resistance gene has been reported on rice chromosome 2, suggesting that the gene in MN62M is probably a novel gene.

\section{Candidate genes associated with RGM resistance}

Genes within the target region were identified by taking into account the physical location of the interval markers located at $310-420 \mathrm{~kb}$ on the short arm of rice chromosome 2. The total number of genes identified within the regions (Additional file 3: Table S2), after excluding the hypothetical and transposon/retrotransposon proteins, were 10 transcriptional active genes that encode a ribosomal protein (LOC_Os02g01540), F-box domain and LRR-containing protein (LOC_Os02g01550), 40S ribosomal protein S4 (LOC_Os02g01560), glycosyl hydrolases (LOC_Os02g01590), pentatricopeptide repeat-containing protein (LOC_Os02g01610), RNA recognition motif-containing protein (LOC_Os02g01700), peptidase family C78 domain-containing protein (LOC_Os02g01710), transmembrane protein 120A (LOC_Os02g01720), serine/threonine-protein kinase At1g18390 precursor (LOC_Os02g01730), and U5 small nuclear ribonucleoprotein (LOC_Os02g01740). Two candidate genes (LOC_Os02g01550 and LOC_Os02g01610) are involved in host plant resistance mechanisms and thus considered as the most likely candidate genes. 


\section{Discussion}

Recently, RGM has become a major insect pest of rice in Thailand and other Asian countries (Bentur et al. 2016). The damaged plants show symptoms after the insect is almost ready to emerge as an adult midge. RGM is not considered as a pest that migrates for long distances; it is a weak flier and lives for only a few days as an adult (Jagadeesha Kumar et al. 2009; Rajamani et al. 2004). To our knowledge, there is no report on the migration of RGM in Thailand; it may have been transferred by humans, water, or wind (Janique et al. 2017; Katiyar et al. 2000). The insect pest is not easily controlled even by chemical insecticides (Lakshmi et al. 2006; Sardesai et al. 2001). Development of RGM resistance in rice plants by identifying and introgressing RGM resistance genes is the most convenient and efficient strategy for controlling the pest (Huang et al. 2007; Suvendhu et al. 2014; Venkanna et al. 2018). Several RGMresistant varieties have been developed. However, the development process is impeded by the diverse RGM biotypes (Bentur et al. 2016; Lakshmi et al. 2006).

One of the objectives of the present study was to assess the genetic diversity and biotypes of RGM across the outbreak areas in Thailand when compared with the RGM from South India and gall midge from P. distichum. Seventeen RGM populations from rice fields in central, north, and northeast Thailand, one population from P. distichum in the north of Thailand, and a Kerala population were classified into two distinct groups on the basis of the partial COI sequences. The first group consisted of all RGM populations from Thailand. The second group was composed of the gall midge from P. distichum and RGM from Kerala, India. The RGM from the Kerala population was genetically more closely related to the P. distichum gall midge from CRI, Thailand (it could not survive on rice plants; data not shown) than the RGM populations found in Thailand. The result confirmed those of previous studies (Jairin 2009; Janique et al. 2017; Katiyar et al. 2000), indicating the existence of an RGM species complex in Asia. RGMs from Southeast Asia are genetically different from those in South Asia, and a distinct species among them has been proposed (Katiyar et al. 2000).

The genetic diversity of RGM in Thailand has been reported using DNA markers (Jairin et al. 2009; Tayathum et al. 2004). No significant genetic differentiation by geographical region has been found in Thailand. Only genetic diverges found in some populations in the mountain range (Janique et al. 2017). In Thailand, different biotypes of RGM populations have also been observed (Jairin et al. 2009; Tayathum et al. 1995). Because of the lack of a differential set of resistant varieties with known resistance genes, biotypes of the RGM populations in Thailand have not been intensively studied. In this study, we used four resistant rice varieties carrying GM1, GM12, and unknown resistance genes to differentiate the RGM biotypes in Thailand. We classified at least four different RGM biotypes. Therefore, the complex of biotypes in Thailand needs to be verified. Development of a differential set of resistant varieties, with known resistance genes, is also necessary for the identification of RGM biotypes. Our previous study found no correlation between genetic diversity and Thai RGM biotypes identified by phenotypical rice/midge observation (Jairin et al. 2009). In this study, we observed no relationship between the genetic diversity and biotypes of some RGMs collected from north and northeast Thailand. For example, the 
genetic diversity of UBN, Nong Khai (NKI), and Nan (NAN) populations was closely related, but their reactions to the resistance genes were different.

Resistant varieties have been considered a perfect method to control RGM. Identification of new sources of RGM resistance would help breeders to provide rice varieties with a broad range of durable gall midge resistance. The Thai landrace MN62M, which has a broad spectrum of RGM resistance against Thai biotypes, was selected for the present study to map a new RGM resistance gene. We performed highresolution mapping of a new RGM resistance locus, GM12, on the short arm of chromosome 2 in MN62M. To our knowledge, this is the first RGM resistance gene reported on chromosome 2 . The locus is located between SNP markers S2_76222 and S2_419160 within the physical position of $75 \mathrm{~kb}$ and $420 \mathrm{~kb}$ and has a size of approximately $345 \mathrm{~kb}$. Further confirmed by SSR markers, the resistance gene is located between marker RM6800 and S2_419160, with a size of approximately $100 \mathrm{~kb}$.

To date, 11 RGM resistance genes have been identified in cultivated rice: GM1 on chromosome 9 from W1263 (Biradar et al. 2007; Reddy et al. 1997), GM2 on chromosome 4 from Phalguna (Mohan et al. 1994; Rajyashri et al. 1998), GM3 on chromosome 4 from RP2068-18-3-5 (Kumar et al. 1998a; Sama et al. 2014), GM4 on chromosome 8 from Abhaya (Mohan et al. 1997; Srivastava et al. 1993), GM5 from ARC5984 (Kumar et al. 1998b), GM6 on chromosome 4 from Dukong 1 (Tan et al. 1993; Katiyar et al. 2001), GM7 on chromosome 4 from RP2333-156-8 (Kumar et al. 1999; Sardesai et al. 2002), GM8 on chromosome 8 from Jhitpiti and Aganni (Jain et al. 2004; Kumar et al. 2000), GM9 from Madhuri line 9 (Shrivastava et al. 2003), GM10 from BG380-2 (Kumar et al. 2005), and GM11 on chromosome 12 from CR57-MR1523 and Suraksha (Himabindu et al. 2010). Eight of the 11 resistance genes have been mapped to rice chromosomes (Nair et al. 2011), and only three candidate genes for GM2, GM3, and GM4 have been cloned and characterized (Bentur et al. 2016). GM5, GM9, and GM10 have not yet been mapped to rice chromosomes. Rice varieties ARC5984 and BG380-2 carrying GM5 and GM10, respectively, were susceptible to all RGM populations used in this study, and GM9 behaves as a dominant resistance gene (Shrivastava et al. 2003). Therefore, we believe that GM12 from MN62M is a new RGM recessive gene.

Of the 10 annotated genes identified in the genomic region surrounding the GM12 locus, two genes encoding the pentatricopeptide repeat protein (LOC_Os02g01610) and F-box domain and LRR-containing protein (LOC_Os02g01550) have been reported to be involved in the defense mechanism against biotic stresses ( Li et al. 2012; Mohapatra et al. 2014; Yasala et al. 2012). The pentatricopeptide repeat protein is involved in a broad spectrum of resistance against biotic stresses and plays a vital role in plant defense mechanisms against pathogens (Saha et al. 2007; Yasala et al. 2012). The F-box domain-containing protein plays a very important role in plant development and defense mechanism (Kuroda et al. 2002; Yasala et al. 2012). Therefore, the two genes identified in this study could be potential candidates for the new RGM resistance gene and may be directly or indirectly associated with gall midge resistance. However, further analyses are needed to confirm the involvement of the candidate genes in the expression of RGM resistance. 
The new RGM-resistance locus identified in this study provides SNP and SSR markers (Additional file 4: Figure S2) for developing RGM-resistant varieties through MAS as well as for cloning the RGM resistance gene. The new resistance gene also provides important information for the identification of RGM biotypes in Thailand or Southeast Asia. Therefore, we strongly believe that our findings can help in the management of RGM in Thailand and Southeast Asian countries. Development of rice varieties with resistance to gall midge is often impeded by the emergence of new RGM biotypes (Bentur et al. 2003). A combination of different resistant mechanisms, for example, by pyramiding GM1 and GM12 with SSR and SNP markers from this study, would be effective in ensuring resistance durability. Currently, we are using these associated markers in a breeding program for introgression of GM1 and GM12 into popular rice varieties KDML105, and RD6.

\section{Conclusions}

The results of our study supported the previous finding that RGMs from Southeast Asia are different from those in South Asia. Most of the RGM resistance genes identified in South Asia cannot be used in Thailand because of the biotype differences. In the present study, we have reported a new RGM resistance gene designated as GM12 on the short arm of chromosome 2 in Thai rice landrace MN62M. We also identified SNP and SSR markers that can be used in MAS. The new resistance gene provides important information for the identification of RGM biotypes and MAS to develop cultivars with broadspectrum resistance to RGM in Thailand and Southeast Asian countries.

\section{Methods}

\section{Mapping population}

The Thai rice landrace MN62M was used as the donor and crossed with KDML105, a premium fragrant rice cultivar, during the wet season of 2017 at the Phrae Rice Research Center (PRRC) to generate $F_{1}$. The $F_{1}$ seeds were selfed to generate $F_{2}$ seeds. Individual $F_{2}$ plants were planted in a rice field in the wet season of 2018 , and $300 \mathrm{~F}_{2}$ individuals were randomly selected for phenotypic evaluation. Of the 300 individuals, 144 were selected for genotypic analysis. Leaves of the selected $F_{2}$ plants were collected for DNA extraction, genetic tagging and mapping, and identification of the RGM-resistant locus. $F_{3}$ seeds were used for phenotyping for RGM resistance at the Ubon Ratchathani Rice Research Center (URRC) in the dry season of 2018.

Insect populations

The RGM populations were collected from fields in Loei (LEI), UBN, Nong Bua Lam Phu (NBP), NKI, Buri Ram (BRR), NAN, Chiang Mai (CMI), CRI, Phrae (PRE), Mae Hong Son (MHS), Phichit (PCT), Phetchabun (PCB), Chai Nat (CNT), and Lop Buri (LBR) Provinces (Fig. 1). The RGMs from all the collection sites were used for the genetic diversity analysis. The RGMs from BRR, CMI, PRE, MHS, UBN, NKI, NAN, and CRI were used for the evaluation of resistance in rice cultivars at PRRC and URRC in the wet seasons of 2017 and 
2018 , respectively. The RGM population collected from UBN was used for resistant screening in the $F_{3}$ generation of the cross KDML105 $\times$ MN62M.

Sequence alignment and phylogeny analysis

The genomic DNA was extracted using NucleoSpin ${ }^{\circledR}$ Tissue (Macherey-Nagel, Germany). The partial gene sequence of $\mathrm{COI}$ in RGM was amplified using the forward primer $5^{\prime}-$

CATTGGAGATGACCAAATTTATAATG-3' and reverse primer 5'-TAAACTTCAGGGTGACCAAAAAATCA-3' (Folmer et al. 1994). The PCR-amplified product was purified using the QIAquick PCR Purification Kit (Qiagen, Germany), according to the manufacturer's instructions. The purified product was sequenced using Sanger's sequencing method at the First BASE Laboratories (Selangor, Malaysia). Sequence alignment and editing were performed using MEGA7 (Kumar et al. 2016). COls were aligned together and used for phylogenetic tree construction. The alignments were performed using ClustalW (Goujon et al. 2010) in MEGA7. Gall midges of the weed Paspalum distichum L. collected from CRI and RGM from Kerala, India (GenBank Accession No. KC506565) (Kattali et al. 2015), were used as the outgroups in the phylogeny analysis.

Evaluation for RGM resistance

A total of $300 \mathrm{~F}_{2: 3}$ lines from the KDML105 $\times$ MN62M cross were evaluated for RGM resistance at the seedling stage at URRC. In 2018, an RGM population was collected from a rice field in UBN Province. The RGM population was maintained on susceptible cultivar RD49 in a greenhouse at URRC. The seedbox screening test (Heinrichs et al. 1985) was conducted to evaluate RGM resistance in the test lines. Twenty seeds of each test entry, susceptible (RD1), and resistance (W1263) controls were sown in seedboxes $(100 \mathrm{~cm} \times 60 \mathrm{~cm} \times 15 \mathrm{~cm}$ ) containing well-puddled soil in 30-cm rows. Fifteen days after sowing, the seedlings were infested with adult RGM females (one midge per 10 seedlings). When all seedlings of the susceptible variety produced galls, SES scoring (IRRI 2013) was used to assign a resistance score to each genotype.

DNA extraction

The samples included $144 \mathrm{~F}_{2}$ plants from the KDML105 $\times$ MN62M cross, and the two parents were planted in a rice field at PRRC, Thailand. Genomic DNA was isolated from the leaves of each sample by using the (modified) standard cetyltrimethylammonium bromide method (Doyle and Doyle 1987) and quantified with a Nanodrop-1000 spectrophotometer (Thermo Fisher Scientific).

SNP genotyping

Genotyping for the mapping population and parents was performed using the next-generation sequencebased genotyping method. A sequencing protocol with the ApeKI enzyme was used to generate SNP data for each $F_{2}$ individual and their parents. Libraries of the selected resistant and susceptible plants were prepared as described by Jairin et al. (2019). The libraries were sequenced using the lon $S 5^{\mathrm{TM}} \mathrm{XL}$ 
Sequencer (Thermo Fisher Scientific). All sequencing data were analyzed using lon Torrent ${ }^{\text {TM }}$ Suite Software Alignment Plugin V5.2.2 (Thermo Fisher Scientific), with the Nipponbare genome (Kawahara et al. 2013) as the reference. SNPs were identified using GATK (McKenna et al. 2010). Parental SNPs were compared to identify SNPs between the two parents of the $F_{2}$ population. Informative SNPs were detected using TASSEL 5 (Bradbury et al. 2007).

SSR genotyping

A total of 25 SSR markers covering the GM12 region on the short arm of chromosome 2 were used to screen KDML105 and MN62M. Only polymorphic SSR markers were selected to confirm and map the RGM-resistant locus in MN62M. The SSR markers were obtained from the public database released by Gramene (http://www.gramene.org/). PCR was performed using a $10 \mu$ reaction mixture containing $25 \mathrm{ng}$ of template DNA, $4 \mu$ l of each primer $(0.5 \mu \mathrm{M})$, and $8 \mu$ of the Master Mix with the Standard Buffer of OneTaq ${ }^{\circledR}$ Hot Start DNA Polymerase (NBE). The template DNA was initially denatured at $94^{\circ} \mathrm{C}$ for 5 min. Amplification was performed for 35 cycles $\left(1 \mathrm{~min}\right.$ at $94^{\circ} \mathrm{C}, 1 \mathrm{~min}$ at $55^{\circ} \mathrm{C}$, and $2 \mathrm{~min}$ at $72^{\circ} \mathrm{C}$ ), followed by $5 \mathrm{~min}$ at $72{ }^{\circ} \mathrm{C}$. The amplified product was electrophoresed on a $6 \%$ denaturing silver-stained polyacrylamide gel. Then, the polymorphic markers were used to assay the $144 F_{2}$ plants for genetic mapping of GM12.

Linkage map construction, QTL analysis, and candidate gene analysis

Linkage analysis was performed using the $144 \mathrm{~F}_{2}$ individuals. Segregation distortion of the individual markers was calculated using the chi-square test on a 1:2:1 basis. The SNP markers with more than $30 \%$ missing data in the mapping population and SNPs that were not polymorphic in the parents but polymorphic in the mapping populations were excluded from the analysis. The remaining SNP markers were used to construct genetic linkage maps in JoinMap 4.1 (Van Ooijen 2006) by using the parameters set for the $F_{2}$ population type. Kosambi mapping function (Kosambi 1944) was used to convert recombination fractions to distance in $\mathrm{cM}$ (centiMorgans).

QTL maps of the RGM resistance phenotype from the $F_{2: 3}$ family was analyzed using MapQTL 6.0 (Van Ooijen 2004). The MQM mapping method was used to detect significant associations between the phenotypic trait and marker data set. Significant LOD thresholds were determined using the permutation test at 1,000 permutations per trait. The PVE by a single QTL was estimated based on the population variance found within the progeny by maximum likelihood estimation.

In silico analysis of putative candidate genes in the targeted region was performed with the available sequence annotation database http://rapdb.dna.affrc.go.jp. The location and function of these genes were noted to identify the putative candidate for gall midge resistance.

\section{Abbreviations}


RGM:Rice gall midge, PVE:Phenotypic variance explained, QTL:Quantitative trait locus, LOD:Logarithm of the odds, SNP:Single nucleotide polymorphism, SSR:Simple sequence repeat

\section{Additional Files}

Additional file 1: Table S1. Pest severity (percentage of plants infested with galls) in the $F_{3}$ population. (XLSX $22 \mathrm{~kb})$

Additional file 2: Figure S1. SNP-based linkage map of the rice gall midge resistance gene. (DOCX $157 \mathrm{~kb}$ )

Additional file 3: Table S2. Candidate genes associated with the rice gall midge resistance in the GM12 region. (XLSX $12 \mathrm{~kb}$ )

Additional file 4: Figure S2. Amplification pattern of the most closely linked markers in susceptible and resistant $\mathrm{F}_{2}$ plants. (DOCX $49 \mathrm{~kb}$ )

\section{Declarations}

\section{Ethics approval and consent to participate}

Not applicable.

\section{Consent for publication}

Not applicable.

\section{Availability of data and materials}

All necessary data supporting this article are provided within the article and the additional files.

\section{Competing interests}

The authors declare that they have no competing interests.

\section{Funding}

This study was supported by a research grant from the Rice Department, Thailand (Project No. 27363).

\section{Authors' contributions}

$\mathrm{PL}$ and SK performed the genetic mapping and wrote the manuscript. The genome sequence was generated using the lon S5 ${ }^{\text {TM }}$ XL platform by AS CU RK and PL. KD SK PL KB and PY were responsible for material plant, field management, RGM populations and evaluation for RGM resistance. PV and YP analyzed the data. VC and PV revised the manuscript. JJ conceived designed the experiments, led the project, and played major roles in the writing of the manuscript. 


\section{Acknowledgments}

We thank the International Rice Research Institute for providing seeds for the gall midge resistant varieties used in this study. Many thanks to our colleagues at the Ubon Ratchathani Rice Research Center and Phrae Rice Research Center for their assistance with both laboratory work and field work. We are thankful to Dr. Poonsak Mekwattanakarn for critical comments on the manuscript.

\section{Author information}

${ }^{1}$ Ubon Ratchathani Rice Research Center, Mueang, Ubon Ratchathani 34000, Thailand. ${ }^{2}$ Phrae Rice Research Center, Mueang, Phrae 54000, Thailand. ${ }^{3}$ Chiang Rai Rice Research Center, Phan, Chiang Rai, 57120, Thailand. ${ }^{4}$ Division of Rice Research and Development, Rice Department, Chatuchak, Bangkok 10900, Thailand

\section{References}

1. Atray I, Bentur JS, Nair S (2015) The Asian rice gall midge (Orseolia oryzae) mitogenome has evolved novel gene boundaries and tandem repeats that distinguish its biotypes. PloS one10:e0134625

2. Bentur JS (1987) Occurrence of a virulent rice gall midge Orseolia oryzae (Wood-Mason) biotype (?) in Andhra Pradesh, India. Inter Rice Res Notes 12:33-34

3. Bentur JS, Pasalu IC, Sarma NP, Prasada Rao U, Mishra B (2003) Gall midge resistance in rice. Directorate of Rice Research, Hyderabad

4. Bentur JS, Rawat N, Divya D, Sinha DK, Agarrwal R, Atray I et al (2016) Rice-gall midge interactions: Battle for survival. J Insect Physiol 84:40-49

5. Biradar SK, Sundaram RM, Thirumurugan T, Bentur JS, Amudhan S, Shenoy VV et al (2007) Identification of flanking SSR markers for a major rice gall midge resistance gene $G m 1$ and their validation. Theor Appl Genet (2004) 109:1468-1473

6. Bradbury PJ, Zhang Z, Kroon DE, Casstevens TM, Ramdoss Y, Buckler ES (2007) TASSEL: Software for association mapping of complex traits in diverse samples. Bioinformatics 23:2633-2635

7. Divya D, Himabindu K, Nair S, Bentur JS (2015) Cloning of a gene encoding LRR protein and its validation as candidate gall midge resistance gene, $G m 4$, in rice. Euphytica 203:185-195

8. Doyle JJ, Doyle JL (1987) A rapid DNA isolation procedure for small quantities of fresh leaf tissue. Phytochemical bull 19:11-15

9. Folmer O, Black M, W. Hoeh W, Lutz R, Vrijenhoek R (1994) DNA primers for amplification of mitochondrial cytochrome $\mathrm{c}$ oxidase subunit I from diverse metazoan invertebrates. Mol Mar Biol Biotechnol 3(5):294-299

10. Goujon M, McWilliam H, Li W, Valentin F, Squizzato S, Paern J et al (2010) A new bioinformatics analysis tools framework at EMBL-EBI. Nucleic Acids Res 38:W695-W699 
11. Heinrichs EA, Medrano FG, Rapusas HR (1985) Genetic evaluation for insect resistance in rice. International Rice Research Institute, Los Baños

12. Himabindu K, Suneetha K, Sama VSAK, Bentur JS (2010) A new rice gall midge resistance gene in the breeding line CR57-MR1523, mapping with flanking markers and development of NILs. Euphytica 174:179-187

13. Huang B, Zhang Y, Xie Z, Zhang G, Xiao H, Li H et al (2007) Molecular assisted breeding for resistant varieties against Asian rice gall midge in south China. Mol Plant Breed 2007 5(4):507-514

14. IRRI (2013) Standard evaluation system for rice. International Rice Research Institute, Los Baños

15. Jagadeesha Kumar BJ, Chakravarthy AK, Doddabasappa B, Basavaraju BS (2009) Biology of the rice gall midge, Orseolia oryzae (Wood-Mason) in southern Karnataka. Karnataka J of Agric Sci 22:535537

16. Jain A, Ariyadasa R, Kumar A, Srivastava MN, Mohan M, Nair S (2004) Tagging and mapping of a rice gall midge resistance gene, $G m 8$, and development of SCARs for use in marker-aided selection and gene pyramiding. Theor Appl Genet 109:1377-1384

17. Jairin J, Sansen K, Teangdeerith S, Leelakud P, Kawichai R, Sriratanasak W, Chiengwattana N (2009) Genetic diversity and biotypes of the rice gall midge in Thailand. Thai Rice Res J 3:39-47 (in Thai with English abstract)

18. Jairin J, Vejchasarn P, Somjai T, Srivilai K, Darwell K, Leelagud P et al (2019) Identification of QTLs for blast, bacterial blight, and planthopper resistance using SNP-based linkage maps from two recombinant inbred rice lines. American J Plant Sci 10:1-19

19. Janique S, Sriratanasak W, Ketsuwan K, Jairin J, Jeratthitikul E (2017) Phylogeography of the Asian rice gall midge Orseolia oryzae (Wood Mason) (Diptera: Cecidomyiidae) in Thailand. Genetica 145:37-49

20. Katiyar SK, Chandel G, Tan Y, Chandel G, Xu Y, Zhang Y et al (2000) Biodiversity of Asian rice gall midge (Orseolia oryzae Wood Mason) from five countries examined by AFLP analysis. Genome 43:322-332

21. Katiyar SK, Tan Y, Huang B, Chandel BG, Xu Y, Zhang Y et al (2001) Molecular mapping of gene Gm$6(\mathrm{t})$ which confers resistance against four biotypes of Asian rice gall midge in China. Theor Appl Genet 103:953-961

22. Kattali M, Kottickal LV, Sudheer S, Ramesh N (2015) Phylogenetic status of Asian rice gall midge, Orseolia oryzae in the Cecidomyiidae family. Thai J Genet 8:134-142

23. Kawahara Y, de la Bastide M, Hamilton JP, Kanamori H, McCombie WR, Ouyang S et al (2013) Improvement of the Oryza sativa Nipponbare reference genome using next generation sequence and optical map data. Rice 6:1-10

24. Khush GS (1977) Breeding for resistance in rice. Ann NY Acad Sci 287:296-308

25. Kosambi DD (1944) The estimation of map distance from recombination values. Ann Eugenics 12:172-175 
26. Kumar A, Shrivastava MN, Shukla BC (1998a) Inheritance and allelic relationship of gall midge biotype-1 resistance gene(s) in some new donors. Oryza 35:70-73

27. Kumar A, Shrivastava MN, Sahu RK (1998b) Genetic analysis of ARC5984 for gall midge resistance - a reconsideration. Rice Genet Newsl 15:142-143

28. Kumar A, Shrivastava MN, Shukla BC (1999) A new gene for resistance to gall midge in rice cultivar RP2333-156-8. Rice Genet Newsl 16:85-87

29. Kumar A, Bhandarkar S, Pophlay DJ, Shrivastava MN (2000) A new gene for gall midge resistance in rice accession Jhitpiti. Rice Genet Newsl 17:83-84

30. Kumar A, Jain A, Sahu RK, Shrivastava MN, Nair S, Mohan M (2005) Genetic analysis of resistance genes for the rice gall midge in two rice genotypes. Crop Sci 45:1631-1635

31. Kumar S, Stecher G, Tamura K (2016) MEGA7: molecular evolutionary genetics analysis version 7.0 for bigger datasets. Mol Biol Evol 33:1870-1874

32. Kuroda H, Takahashi N, Shimada H, Seki M, Shinozaki K, Matsui M (2002) Classification and expression analysis of Arabidopsis F-box-containing protein genes. Plant Cell Physiol 43:1073-1085

33. Lakshmi PV, Amudhan S, Bindu KH, Cheralu C, Bentur JS (2006) A new biotype of the Asian rice gall midge Orseolia oryzae (Diptera: Cecidomyiidae) characterized from the Warangal population in Andhra Pradesh, India. Int J Trop Insect Sci 26:207-211

34. Li S, Sun Q, Hu M, Li S, Zhu Y, Zhu Y (2012) Phylogenetic genomewide comparisons of the pentatricopeptide repeat gene family in indica and japonica Biochem Genet 50:978

35. McKenna A, Hanna M, Banks E, Sivachenko A, Cibulskis K, Kernytsky A et al (2010) The Genome Analysis Toolkit: A MapReduce framework for analyzing next-generation DNA sequencing data. Genome Res 20(9):1297-1303

36. Mohan M, Nair S, Bentur JS, Rao UP, Bennett J (1994) RFLP and RAPD mapping of rice Gm2 gene that confers resistance to biotype 1 of gall midge (Orseolia oryzae). Theor Appl Genet 87:782-788

37. Mohan M, Sathyanarayanan PV, Kumar A, Srivastava MN, Nair S (1997) Molecular mapping of a resistance-specific PCR-based marker linked to a gall midge resistance gene (Gm/t) in rice Theor Appl Genet 95:777-782

38. Mohapatra S, Panda RS, Mohanty SK, Behera L, Sahu SC, Prakash A (2014) In silico analysis of gall midge resistance gene $G m 4$ in rice cultivar PTB10. Oryza 51(1):34-42

39. Nair S, Bentur JS, Sama VSAK (2011) Mapping gall midge resistance genes: towards durable resistance through gene pyramiding. In: Muralidharan, K, Siddiq, EA (eds) Genomics and Crop Improvement: Relevance and Reservations, ANGR Agricultural University, Hyderabad, pp 256-264

40. Oupkaew P, Pusadee T, Sirabanchongkran A, Rerkasem K, Jamjod S, Rerkasem B (2011) Complexity and adaptability of a traditional agricultural system: case study of a gall midge resistant rice landrace from northern Thailand. Genet Resour Crop Evol 58:361-372

41. Pusadee T, Oupkaew P, Rerkasem B, Jamjod S, Schaal BA (2014) Natural and human-mediated selection in a landrace of Thai rice (Oryza sativa). Ann Appl Biol 165(2):280-292 
42. Rajamani S, Pasalu IC, Mathur KC, Sain M (2004) Biology and ecology of rice gall midge. In: Bennett J, Bentur JS, Pasalu IC, Krishnaiah K (eds) New Approach to Gall Midge Resistance in Rice, Hyderabad, India, pp 7-16

43. Rajyashri KR, Nair S, Ohmido N, Fukui K, Kurata N, Sasaki T et al (1998) Isolation and FISH mapping of Yeast Artificial Chromosomes (YACs) encompassing an allele of the Gm2 gene for gall midge resistance in rice. Theor Appl Genet 97:507-514

44. Ramaswamy C, Jatileksono T (1996) Inter-country comparison of insect and disease losses. In: Evenson RE, Herdt RW, Hussain M (eds) Rice Research in Asia: Progress and Priorities CABI Publ. Wallingford pp 305-316

45. Reddy VA, Siddiq EA, Rao UP, Bentur JS (1997) Genetics of resistance to rice gall midge (Orseolia oryzae). Indian J Genet 57:361-372

46. Saha D, Prasad AM, Srinivasan R (2007) Pentatricopeptide repeat proteins and their emerging roles in plants. Plant Physiol Biochem 45(8):521-534

47. Sama VSAK, Rawat N, Sundaram RM, Himabindu K, Naik BS, Viraktamath BC et al (2014) A putative candidate for the recessive gall midge resistance gene gm3 in rice identified and validated. Theor Appl Genet 127:113-124

48. Sardesai N, Rajyashri KR, Behura SK, Suresh Nair S, Mohan M (2001) Genetic, physiological and molecular interactions of rice and its major dipteran pest, gall midge. Plant Cell Tissue Organ Culture 64:115-131

49. Shrivastava MN, Kumar A, Bhandarkar S, Shukla BC, Agrawal KC (2003) A new gene for resistance in rice to Asian rice gall midge (Orseolia oryzae WoodMason) biotype 1 population at Raipur, India. Euphytica 130:143-145

50. Srivastava MN, Kumar A, Shrivastava SK, Sahu RK (1993) A new gene for resistance to gall midge in rice variety Abhaya. Rice Genet Newsl 10:79-80

51. Suvendhu DS, Divya D, Rani CVD, Reddy TD, Visalakshmi V, Cheralu C et al (2014) Characterization of gall midge resistant rice genotypes using resistance gene specific markers. J Exp Biol Agric Sci 2(4):439-446

52. Tan Y, Pan Y, Zhang Y, Lixia Z, Xu Y (1993) Resistance to gall midge (GM) Orseolia oryzae in Chinese rice varieties compared with varieties from other countries. Int Rice Res Newsl 18:13-14

53. Tayathum C, Attathom T, Thongphak D, Sripongpankul K (2004) Biology and ecology of rice gall midge. In: Bennett J, Bentur JS, Pasalu IC, Krishnaiah K (eds) New Approach to Gall Midge Resistance in Rice. Proceedings of the International Workshop, Hyderabad, pp 89-98

54. Tayathum C, Junseesommaei N, Srirattanasak V (1995) Biotypes of rice gall midge, Orseolia oryzae (Wood-Mason) in Thailand. In Conference of Entomology and Zoology group. Ministry of Agriculture and Cooperative. Bangkok pp 160-172 (in Thai with English abstract)

55. Van Ooijen JW (2004) MapQTL 5, software for the mapping of quantitative trait loci in experimental populations. Kyazma B.V., Wageningen 
56. Van Ooijen JW (2006) JoinMap ${ }^{\circledR}$ 4, Software for the Calculation of Genetic Linkage Maps in Experimental Populations. Kyazma, B.V: Wageningen

57. Venkanna V, Hari Y, Rukminidevi K, Satish Chandra B, Raju J, Malathi S et al (2018) Markers assisted selection for pyramiding of gallmidge resistance genes in Kavya, a popular rice variety Int $\mathrm{J}$ Curr Microb Appl Sci 7(4):745-753

58. Yasala AK, Rawat N, Sama VSAK, Kudapa HB, Sundaram RM, Bentur JS (2012) In silico analysis for gene content in rice genomic regions mapped for the gall midge resistance genes Plant Omics $\mathrm{J}$ 5(4):405-413

59. Zhao C, Escalante LE, Chen H, Benatti TR, Qu J, Chellapilla S et al (2015) A massive expansion of effector genes underlies gall-formation in the wheat pest Mayetiola destructor. Curr Biol 25:613-620

\section{Figures}

\section{Fig 1}

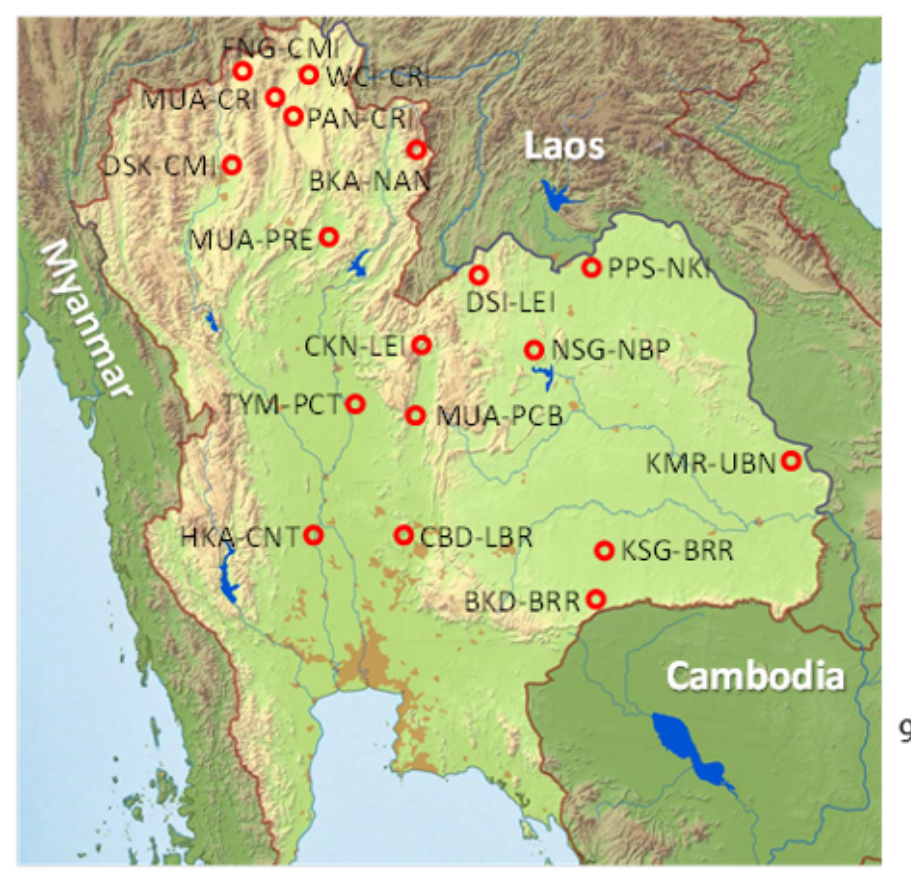

0.005

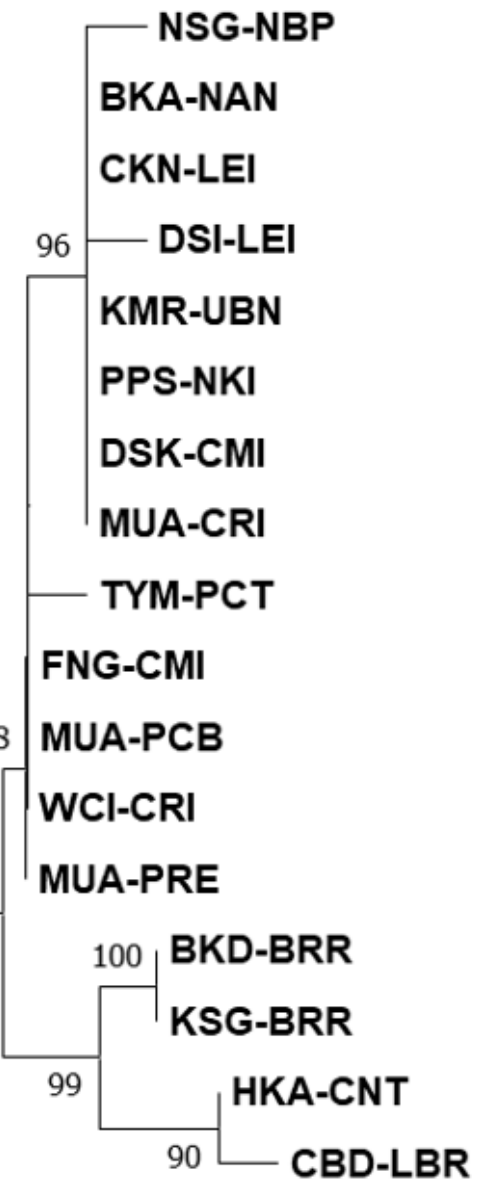

PAN-CRI-Paspalum distichum

Figure 1 
Map of Thailand showing the collection sites for the gall midge populations and phylogenetic tree of COI sequences of rice gall midges in Thailand. The sequence for the Kerala population (India) was derived from GenBank (Accession No. KC506565).

\section{Fig 2}

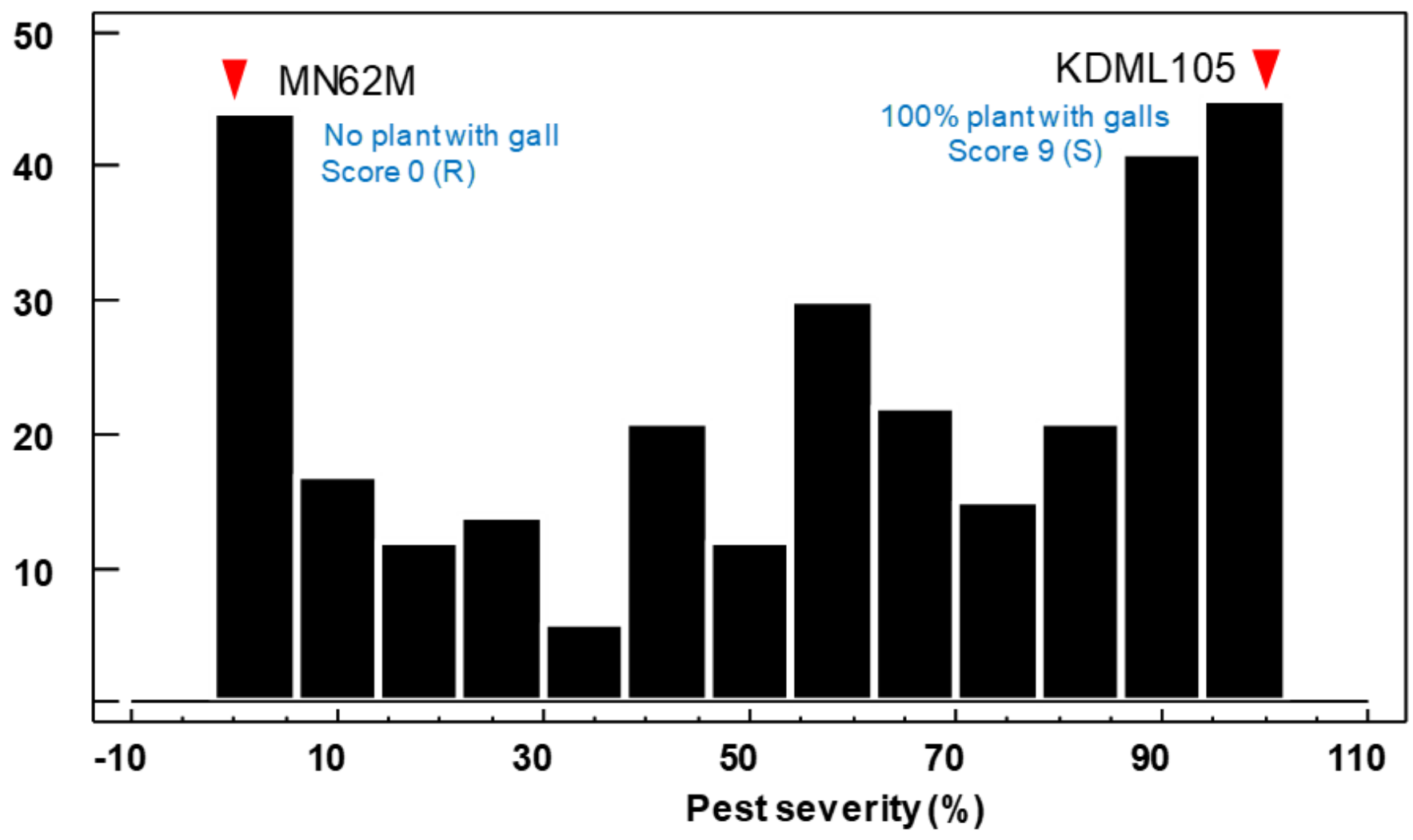

Figure 2

Frequency distribution of pest severity (percentage of plants infested with galls) in the F3 population of the KDML105 $\times$ MN62M cross. The y-axis represents the number of F3 lines. Arrows indicate the values for the two parents. 
Fig 3

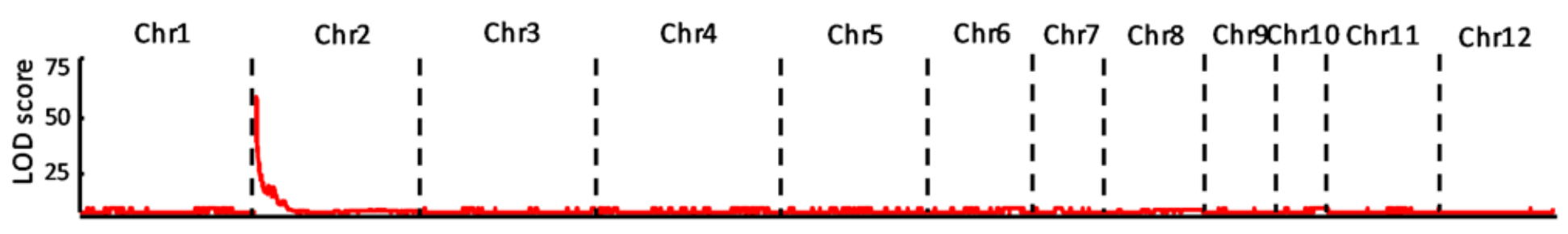

\section{Figure 3}

LOD curves for QTL mapping in the F2:3 population from a cross between KDML105 and MN62M for rice gall midge resistance in the whole genome by using 1,365 SNPs. The horizontal line is the LOD threshold. 
Fig 4

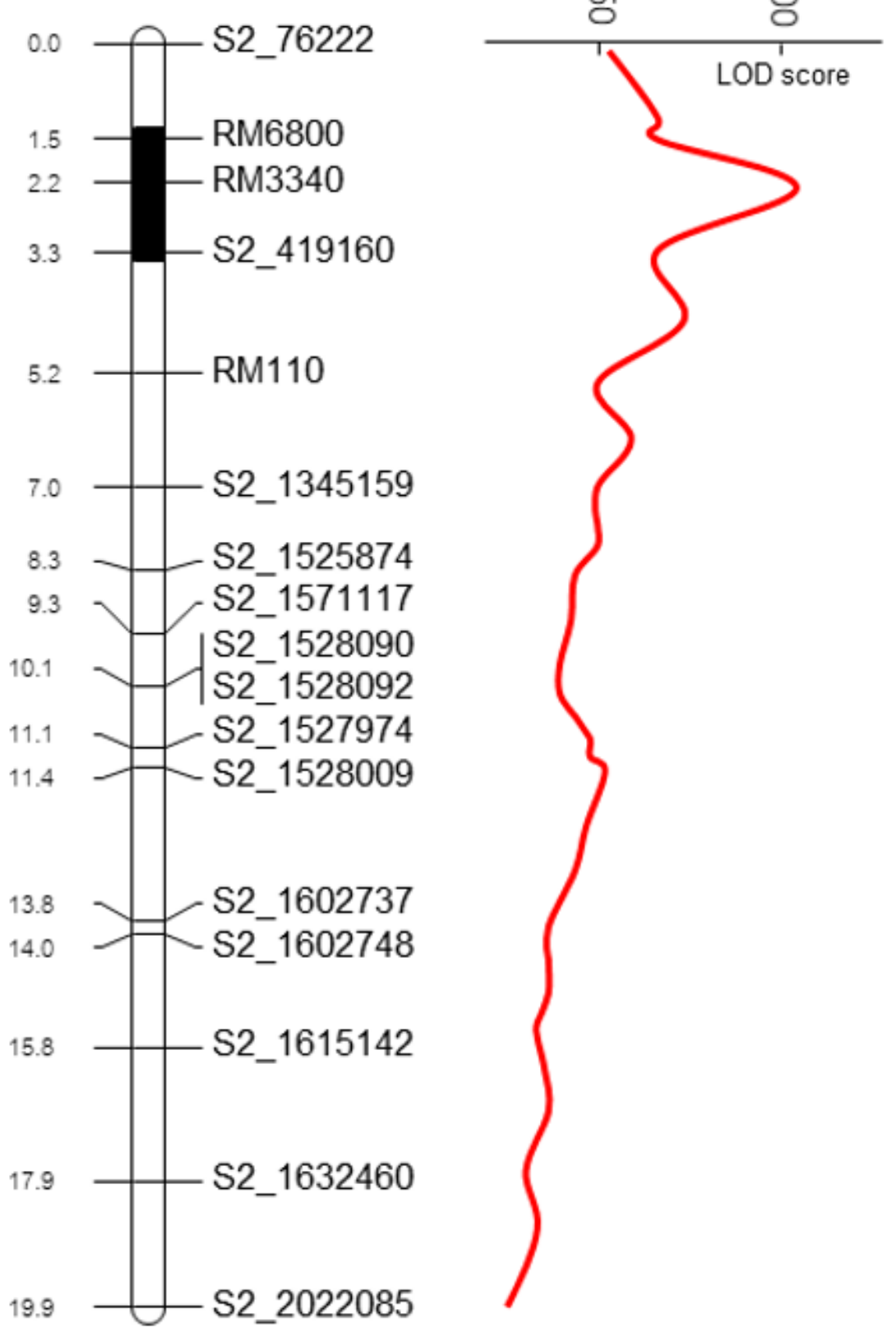

Figure 4

Mapping of the rice gall midge resistance gene (black bar) on the SNP and SSR linkage map for rice chromosome 2 in the F2:3 population. Numbers on the left show genetic distances (cM); next to the linkage map is a LOD curve of the QTL for rice gall midge resistance.

\section{Supplementary Files}

This is a list of supplementary files associated with this preprint. Click to download.

- Tables2Candidategenes.xlsx 
- Tables1Pestseverity.xlsx

- FigureS1.docx

- Figures2.docx 